Bài báo khoa hoc

\title{
Sự thay đổi dòng chảy trên các nhánh: Tonle Sap, Bassac và Mê Công, do hạ thấp đáy sông ở hệ thống sông Cửu Long
}

\section{Nguyễn Nghĩa Hùng ${ }^{1 *}$, Lê Quản Quân ${ }^{1}$}

1 Viện khoa học Thủy lợi miền Nam; hungsiwrr@gmail.com; lequan2005@gmail.com

* Tác giả liên hệ: hungsiwrr@gmail.com; Tel.: +84-988.485.575

Ban Biên tập nhận bài: 22/6/2020; Ngày phản biện xong: 13/8/2020; Ngày đăng bài: $25 / 8 / 2020$

Tóm tắt: Trước sự thay đổi hạ thấp đáy sông trong 20 năm trở lại đây ở trên hệ thống sông Cửu Long theo kết quả địa hình 1998, 2008 và 2018 như các bài báo đã đăng. Nội dung bài báo này nghiên cứu sự tác động của việc hạ thấp tới sự thay đổi tỷ dòng chảy tại nút phân lưu trên sông Mê Công (sông Tiền) và Bassac (sông Hậu), đồng thời xem xét sự thay đồi về sự trao đổi nguồn nước giữa sông Mê Công và biển Hồ. Bài báo sử dụng mô hình toán 1 chiều MIKE11 cho toàn hệ thống sông, sử dụng biên tính toán trong giai đoạn 1998-2018 và áp dụng cho 3 loại địa hình nêu trên để xem xét sự khác biệt. Kết quả cho thấy, xu thế trao đổi nguồn nước vào và ra của sông Mê Công đến biển Hồ khá giảm rõ rệt với sai lệch chuẩn khoảng $\pm 2,9$ tỷ $\mathrm{m}^{3} /$ năm và số ngày trao đổi cũng thay đổi khoảng \pm 18 ngày. Đồng thời, tỉ lệ phân nước trên sông Mê Công chảy về sông Tiền có xu thế tăng trong mùa lũ và mùa kiệt khoảng 7-9\%, ngược lại sông Bassac giảm, điều này làm cho việc điều tiết nguồn nước giữa các khu vực có sự thay đổi đáng kể.

Từ khóa: Hạ thấp lòng dẫn; Tỷ lệ phân lưu; Tonle Sap; Đồng bằng sông Cửu Long.

\section{Mở đầu}

Dòng chảy tại khu vực Phnôm Pênh, trong đó có sự kết nối giữa dòng sông Mê Công với biển Hồ thông qua dòng sông Tonle Sap, dòng chảy phân nhánh tại Chatomuk nơi có sông Mê Công (chảy về Việt Nam gọi là sông Tiền) và sông Bassac (sông Hậu). Đây là khu vực có vai trò rất quan trọng trong việc phân chia nguồn nước về khu vực đồng bằng sông Cửu Long ở Việt Nam (Hình 1). [1] nghiên cứu cho thấy sự kết nối giữa sông Mê Công và biển Hồ đã được hình thành ở thời kỳ đầu kỷ nguyên Holocene (khoảng hơn 11,5 ngàn năm), lúc đó, biển Hồ đang chịu sự tác động của biển Đông. Nguồn nước trung bình hàng năm vào biển hồ khoảng từ $50-80$ tỷ $\mathrm{m}^{3}$ vào khoảng từ cuối tháng 5 đến đầu tháng 3 hàng năm, với mực nước từ $1 \mathrm{~m}$ lên đến $9 \mathrm{~m}$ [2], các tác động đến chế độ thủy văn khu vực Phnom Pênh sẽ tác động rất lớn đến hệ sinh thái [3]. Nếu nói rằng Đồng Tháp Mười và Tứ giác Long Xuyên là "hai lá phổi" của đồng bằng sông Cửu Long thì biển Hồ chính là "trái tim" giữ nhịp đập của dòng chảy và hệ sinh thái trên vùng châu thổ Mê Công. Chính vì thế, nghiên cứu sự trao đổi nước giữa biển Hồ và sông Mê Công đã được nhiều nhóm nghiên cứu làm rõ, nhưng chi tiết và đầy đủ nhất có thể nói là nghiên cứu của dự án WUP-FIN hợp tác giữa Phần Lan và Ủy hội sông Mê Công thực hiện [4]. 


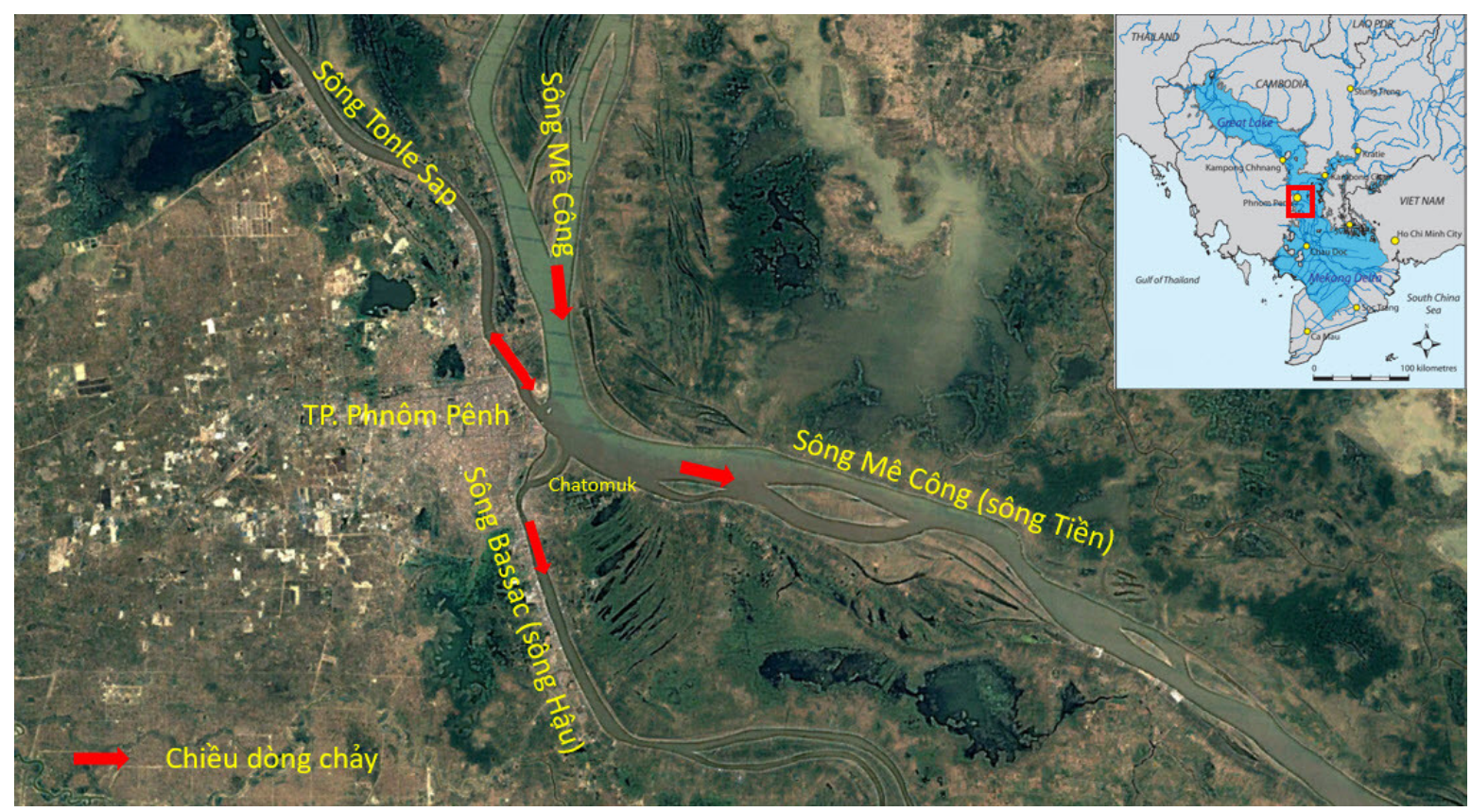

Hình 1. Bản đồ khu vực nghiên cứu.

Theo Ủy ban sông Mê Công, dòng sông Mê Công có khoảng 84 nhánh (phía bờ trái 60 nhánh sông, phía bờ phải 24 nhánh sông) là đóng góp chính cho dòng chảy sông Mê Công. Phía sau Kratie dòng sông bắt đầu có bãi tràn ngập lũ và dòng chảy có xu thế đồng bằng, dòng sông có nhiều nhánh nhưng chủ yếu là sự phân chia lưu lượng mà không góp phần tăng hoặc giảm nguồn nước, lượng mưa trên vùng diện tích sau Kratie không đóng góp đáng kể [2]. Tác động của dòng chảy mùa đến sự trữ nước và cấp nước trở lại nhằm nuôi dưỡng hệ sinh thái biển hồ, đồng thời tạo ra dòng nước ngọt về mùa kiệt thông qua hệ thống sông Tiền và sông Hậu (sông Bassac). Theo tính toán của [5] khi mực nước trên sông Mê Công giảm so với mực nước trên hệ thống sông Tonle Sap, dòng chảy ngược trở lại dòng sông từ biển Hồ ra sông Mê Công bắt đầu xảy ra với thời gian trung bình 238 ngày với tổng lượng nước chảy ngược trở ra là 69,4 tỷ $\mathrm{m}^{3}$, chiếm khoảng 29,7\% tổng lượng nước trên dòng sông Mê Công trong mùa khô. Tuy nhiên nghiên cứu này chỉ ở thời đoạn ngắn và thời kỳ nhiều nước (1999-2001) ba năm liên tục có lũ lớn và đặc biệt lớn. [2] cho thấy lưu lượng lũ tại Kratie có thể đạt $70.000 \mathrm{~m}^{3} / \mathrm{s}$ tương ứng với tần suất $2 \%$ và $72.500 \mathrm{~m}^{3} / \mathrm{s}$ ứng với tần suất $1 \%$ năm, thực tế đã diễn ra lũ xấp xỉ đỉnh lũ $2 \%$ (lũ năm $2000,56.000 \mathrm{~m}^{3} / \mathrm{s}$ ) và lũ năm 1978 vượt $1 \%$ (76.000 $\mathrm{m}^{3} / \mathrm{s}$ ) [6]. Trong khi đó theo tài liệu tính toán từ mực nước thực đo, lưu lượng kiệt nhất tại Kratie khoảng $1.250 \mathrm{~m}^{3} / \mathrm{s}$ diễn ra trong năm 1964, như vậy chênh lệch giữa lưu lượng lũ 1\% và lưu lượng kiệt nhất khoảng 58 lần. [7] Phân tích so sánh kết quả so sánh địa hình đáy sông (1998, 2008, 2018) và phân tích tài liệu mực nước giai đoạn 1998-2018, để đánh giá thực trạng hạ thấp đáy sông và sự thay đổi chế độ thủy triều trong giai đoạn 20 năm trở lại đây thuộc hệ thống sông Cửu Long. Kết quả cho thấy, tổng lượng chênh lệch bùn cát thay đổi giai đoạn 1998-2008 là -388,86 triệu $\mathrm{m}^{3}$ (38,9 triệu $\mathrm{m}^{3} /$ năm) và giai đoạn 2008-2018 là 685,64 triệu $\mathrm{m}^{3}$ (68,6 triệu $\mathrm{m}^{3} /$ năm). Xu thế hạ thấp đáy sông trên hệ thống sông Tiền và sông Hậu giai đoạn 1998-2008 là -8,7 cm/năm, giai đoạn 2008-2018 là -15,3 cm/năm. Tại Tân Châu giai đoạn 1998-2018, mực nước lớn cao giảm $-20 \mathrm{~cm}$, mực nước ròng thấp giảm -70 $\mathrm{cm}$, trong khi đó dải triều tăng $+50 \mathrm{~cm}$, xu thế càng ra biển sự thay đổi càng mạnh. Như vậy, 
câu hỏi đặt ra là liệu việc hạ thấp đáy sông trên hệ thống sông Cửu Long tác động đến tỷ lệ phân chia nguồn nước ở tại nút phân lưu Mê Công và Bassac và sự thay đổi quá trình trao đổi nước với Biển Hồ hay không?

Nghiên cứu này sử dụng mô hình toán $1 \mathrm{D}$ tính toán thủy lực cho vùng châu thổ từ Kratie ra đến biển, có xét đến các kết nối ô lũ để tạo giả 2D, ở phía Việt Nam, lòng dẫn sông được thay đổi theo tài liệu địa hình của nhóm nghiên cứu sẵn có (1998, 2008 và 2018), để xem xét một cách định lượng cho câu trả lời của câu hỏi trên.

\section{Phương pháp và tài liệu sử dụng nghiên cứu}

\subsection{Sử dụng mô hình toán 1 chiều}

Mô hình toán 1 chiều sử dụng phần mềm MIKE 11 kết hợp với việc khai báo bãi ngập lũ để tạo giả $2 \mathrm{D}$ tính toán cho bài toán thủy động lực đã được xây dựng và áp dụng từ lâu cho vùng ĐBSCL, được Viện khoa học Thủy lợi miền Nam xây dựng từ những năm 2002 đến nay. Do đây là một vùng rộng lớn và có hệ thống công trình, sông ngòi, kênh rạch phức tạp vào bậc nhất thế giới, đồng thời cũng là vùng phát triển kinh tế xã hội nhanh mạnh, nên công trình hạ tầng thay đổi nhiều, vì vậy việc có được bộ cơ sở dữ liệu đồng bộ về mặt thời gian và không gian là khó khả thi. Song để đáp ứng được thực tiễn, đã nhiều nghiên cứu phát triển mô hình đã được công bố và được sử dụng cho việc tính toán dự báo hiện đang thực hiện [813].

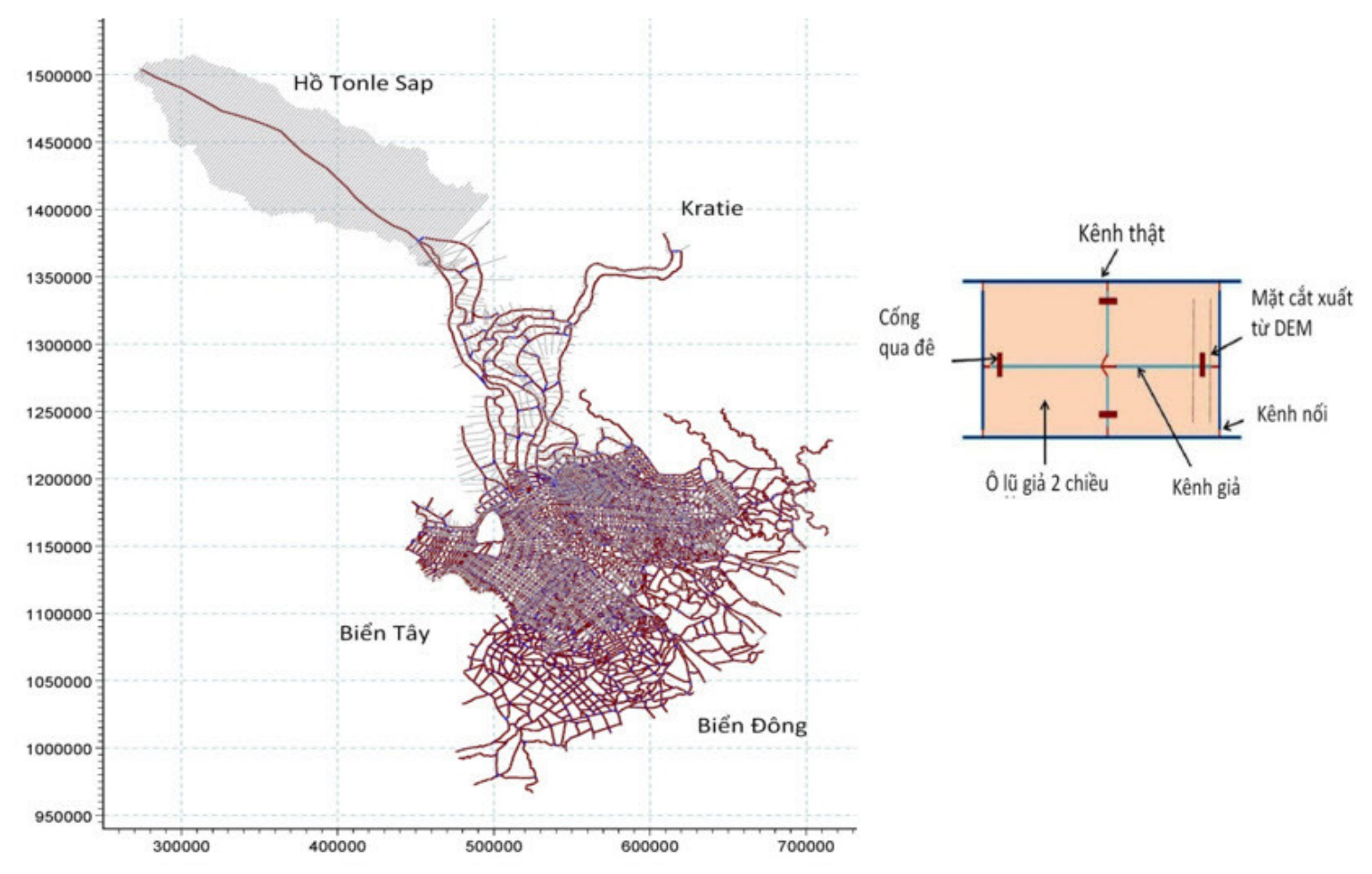

Hình 2. Hệ thống mạng lưới tính toán và các biên sử dụng trong mô hình.

Mô hình được xây dựng với 3.402 nhánh sông, các công trình cống kiểm soát nước 2.260, có 22 biên lưu lượng và 59 biên mực nước (Hình 2). Biên thượng nguồn của mô hình là biên lưu lượng được lấy tại vị trí Kratie, biển Hồ và các nhánh sông phụ lưu, biên hạ nguồn là các biên mực nước trên các cửa sông biển Đông và biển Tây. Các số liệu biên lưu lượng 
và mực nước được cập nhật từ MRC và Đài Khí tượng Thủy văn Nam Bộ. Hệ thống công trình thủy lợi được cập nhật ở vùng ĐBSCL đến năm 2012 và hệ thống địa hình sông, kênh rạch được cập nhật ở mức tối đa theo từng vùng của dự án mà đơn vị nghiên cứu thực hiện.

Tài liệu địa hình lòng dẫn sông: khu vực thuộc hệ thống sông Cửu Long ở Việt Nam, sử dụng tài liệu địa hình lòng dẫn sông 1998, 2008 do MRC cung cấp, 2018 do nhóm nghiên cứu đo đạc. Địa hình lòng sông ở phía Campuchia sử dụng địa hình cũ năm 1998 do MRC cung cấp.

\subsection{Kết quả hiệu chỉnh và kiểm định mô hình}

Dựa trên mô hình cơ sở đã được xây dựng, chúng tôi tiến hành sử dụng 3 tài liệu địa hình các năm 1998, 2008, 2018, so đó tiến hành hiệu chỉnh và kiểm định trong các năm đó: năm 1998 sẽ hiệu chỉnh và kiểm định cho tài liệu năm 1998 trên toàn vùng tính toán, tương tự cho 2008 và 2018, từ đó chúng tôi có được 3 bộ thông số thủy lực tương ứng cho ba mô hình trên để tính toán cho thời đoạn dài 21 năm (1998-2018). Kết quả hiệu chỉnh, kiểm định đều được đánh giá bằng hệ số Nash-sutcliffe, tính theo công thức dưới đây.

$$
\mathrm{NSE}=1-\left[\frac{\sum_{i=1}^{n}\left(Y_{i}^{\text {obs }}-Y_{i}^{\text {sim }}\right)^{2}}{\sum_{i=1}^{n}\left(Y_{i}^{\text {obs }}-Y^{\text {mean }}\right)^{2}}\right]
$$

Trong đó $Y_{i}^{o b s}$ là giá trị thực đo, $Y_{i}^{\text {sim }}$ là giá trị mô phỏng, $Y^{\text {mean }}$ là giá trị trung bình trong chuỗi thực đo và $n$ là tổng số giá trị thực đo. NSE $>0,75$ cho kết quả rất tốt; $0,65<$ $\mathrm{NSE}<0,75$ cho kết quả tốt; $0,50<\mathrm{NSE}<0,65$ cho kết quả trung bình; $\mathrm{NSE}<0,50$ cho kết quả kém.

Bảng 1. Kết quả hiệu chỉnh và kiểm định mô hình.

\begin{tabular}{lcccccc}
\hline \multirow{2}{*}{ Trạm } & \multicolumn{2}{c}{ NSE } & \multicolumn{2}{c}{ NSE } & \multicolumn{2}{c}{ NSE } \\
& \multicolumn{2}{c}{$\mathbf{( 1 9 9 8 )}$} & \multicolumn{2}{c}{$\mathbf{( 2 0 0 8 )}$} & \multicolumn{2}{c}{$\mathbf{( 2 0 1 8 )}$} \\
\hline \multirow{3}{*}{ Tân Châu } & $\mathbf{Q}$ & $\mathbf{W L}$ & $\mathbf{Q}$ & $\mathbf{W L}$ & $\mathbf{Q}$ & $\mathbf{W L}$ \\
Châu Đốc & 0,9 & 0,94 & 0,95 & 0,98 & 0,96 & 0,98 \\
Vàm Nao & 0,75 & 0,89 & 0,9 & 0,96 & 0,91 & 0,94 \\
Mỹ Thuận & & 0,89 & 0,95 & 0,95 & 0,85 & 0,98 \\
Cần Thơ & 0,88 & 0,84 & 0,87 & 0,87 & 0,8 & 0,97 \\
\hline
\end{tabular}

Rõ ràng, trong một hệ thống sông ngòi, kênh rạch rất phức tạp, việc đạt được mở mức độ kiểm định chấp nhận được của mô hình đòi hỏi quá trình thực hiện liên tục và lâu dài. Hình 3 thể hiện kết quả kiểm định sau khi sử dụng các bộ thông số cho các địa hình từng năm 1998,2008 và 2018. 
1998
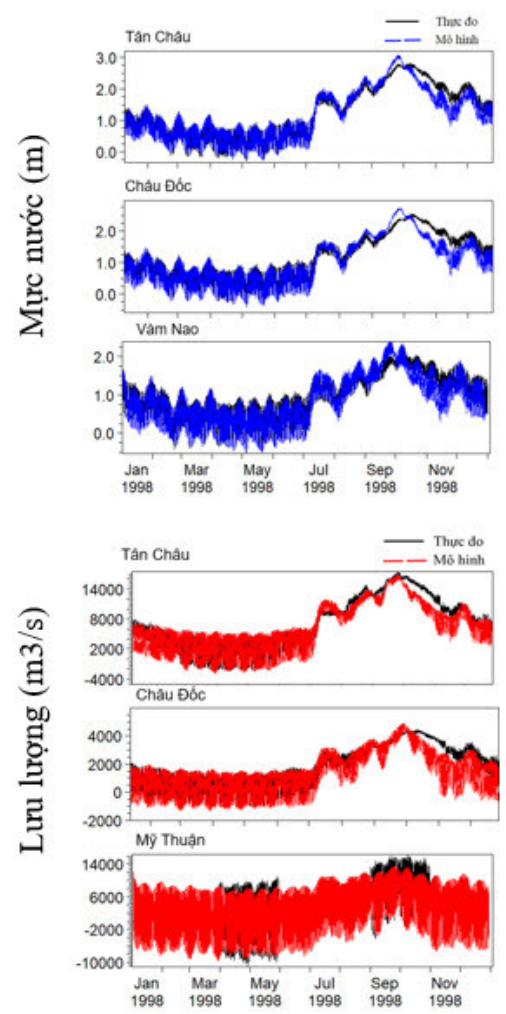

2008
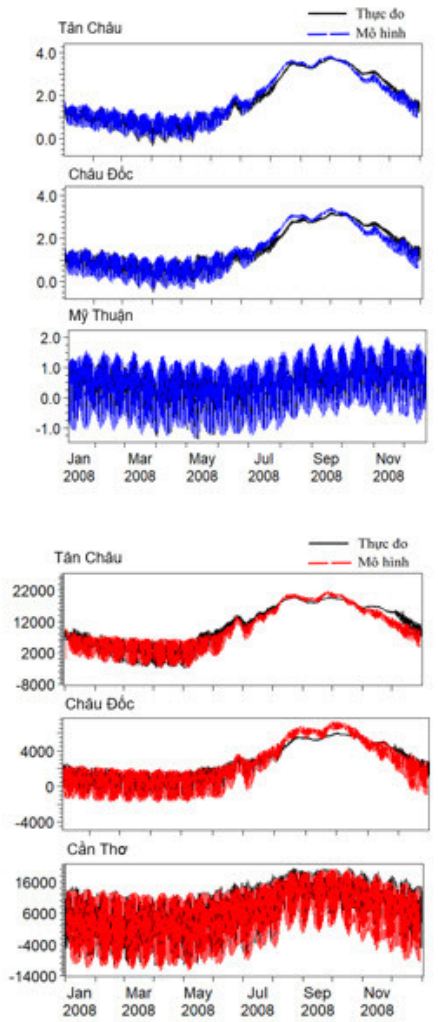

2018
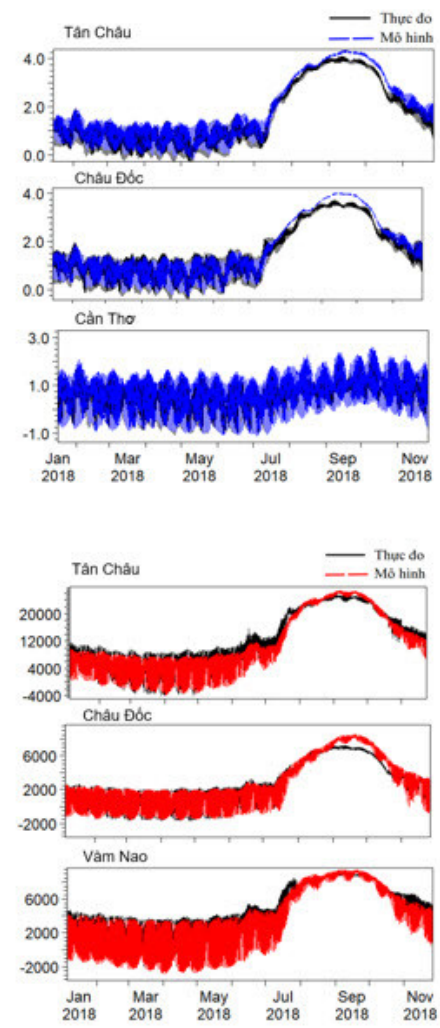

Hình 3. Kết quả kiểm định mực nước, lưu lượng tại trạm Tân Châu, Châu Đốc, Mỹ Thuận.

Kết quả kiểm định các mô hình tương ứng với các tài liệu địa hình khác nhau cho thấy sự tin cậy để đánh giá và phân tích dòng chảy phía thượng nguồn khu vực Phnôm Pênh. Kiểm định mực nước và lưu lượng đều cho kết quả rất tốt, tuy ở một số trạm có sự lệch pha giữa tính toán và thực đo, nhưng với vùng rộng lớn và phức tạp về thủy lực, thì đây là kết quả hoàn toàn có thể sử dụng để thực hiện các nhiệm vụ phân tích đánh giá sau này.

\section{Kết quả và thảo luận}

\subsection{Thay đổi tỉ lệ phân lưu ở sông Mê Công và sông Bassac}

Nguồn nước về ĐBSCL dựa trên hai dòng sông chính là sông Bassac và sông Mê Công tại nút phân lưu Chatomuk phía hạ du của Phnôm Pênh. Đây là khu vực đang phát triển mạnh của nước bạn Campuchia, nhiều hạ tầng đang được đầu tư xây dựng, khai thác cát cũng đã diễn ra khu vực này (trước 2017, sau 2017 đang cấm khai thác) [14], việc khai thác cát cũng sẽ ảnh hưởng đến tỷ lệ phân lưu của khu vực, tuy nhiên do thiếu tài liệu nên chúng tôi không phân tích các tác động về phát triển hạ tầng và khai thác cát ở vùng Campuchia.

Tác động của việc hạ thấp đáy sông ở vùng ĐBSCL có ảnh hưởng đến tỷ lệ phân lưu này hay không được xem xét bằng công cụ mô hình trong giai đoạn 1998-2018. Kết quả tỉ lệ phân lưu được thể hiện ở bảng 2. 
Bảng 2. Kết quả tỉ lệ phân lưu trên sông Mê Công và sông Bassac.

\begin{tabular}{|c|c|c|c|c|c|c|}
\hline \multirow[b]{2}{*}{ Giá trị } & \multicolumn{2}{|c|}{ Địa hình 1998} & \multicolumn{2}{|c|}{ Địa hình 2008} & \multicolumn{2}{|c|}{ Địa hình 2018} \\
\hline & $\begin{array}{c}\text { Q Mê Công } \\
\left(\mathbf{m}^{3} / \mathbf{s}\right)\end{array}$ & $\begin{array}{c}\mathbf{Q} \\
\text { Bassac } \\
\left(\mathbf{m}^{3} / \mathbf{s}\right)\end{array}$ & $\begin{array}{l}\text { Q Mê } \\
\text { Công } \\
\left(\mathbf{m}^{3} / \mathbf{s}\right)\end{array}$ & $\begin{array}{c}\mathbf{Q} \\
\text { Bassac } \\
\left(\mathbf{m}^{3} / \mathbf{s}\right)\end{array}$ & $\begin{array}{c}\text { Q Mê Công } \\
\left(\mathbf{m}^{3} / \mathbf{s}\right)\end{array}$ & $\begin{array}{c}\mathbf{Q} \\
\text { Bassac } \\
\left(\mathbf{m}^{\mathbf{3}} / \mathbf{s}\right)\end{array}$ \\
\hline Lớn nhất (Max) & 24.726 & 9.819 & 24.977 & 10.395 & 26.470 & 6.545 \\
\hline Nhỏ nhất (Min) & 1.888 & 48 & 1.710 & 86 & 1.725 & 20 \\
\hline Trung bình (Average) & 9.545 & 1.700 & 9.507 & 1.779 & 10.054 & 991 \\
\hline Trung vị (Median) & 7.448 & 579 & 7.428 & 624 & 7.737 & 313 \\
\hline Sai lệch chuẩn (Stdev) & 6.040 & 2.177 & 6.133 & 2.294 & 6.634 & 1.396 \\
\hline \multicolumn{7}{|c|}{ Tỷ lệ phân lưu giữa các nhánh (về sông Hậu và sông Tiền) } \\
\hline Lớn nhất (Max) & $72 \%$ & $28 \%$ & $71 \%$ & $29 \%$ & $80 \%$ & $20 \%$ \\
\hline Nhỏ nhất (Min) & $98 \%$ & $2 \%$ & $95 \%$ & $5 \%$ & $99 \%$ & $1 \%$ \\
\hline Trung bình (Average) & $85 \%$ & $15 \%$ & $84 \%$ & $16 \%$ & $91 \%$ & $9 \%$ \\
\hline Trung vị (Median) & $93 \%$ & $7 \%$ & $92 \%$ & $8 \%$ & $96 \%$ & $4 \%$ \\
\hline Sai lệch chuẩn (Stdev) & $74 \%$ & $26 \%$ & $73 \%$ & $27 \%$ & $83 \%$ & $17 \%$ \\
\hline
\end{tabular}

Bảng 2 cho thấy, lưu lượng trong mùa lũ (max) chảy về sông Hậu (Bassac) giảm từ 9.819 $\mathrm{m}^{3} / \mathrm{s}$ tương ứng với địa hình 1998 xuống $6.545 \mathrm{~m}^{3} / \mathrm{s}$ ứng với địa hình 2018 . Như vậy, nước lũ chảy về sông Tiền tăng lên một cách đáng kể trong giai đoạn 2008-2018, trong khi đó giai đoạn 1998-2008 có xu hướng tăng hơn ( $\left.576 \mathrm{~m}^{3} / \mathrm{s}\right)$, tương ứng với tỷ lệ dòng chảy trên sông Tiền/sông Hậu là 72/28 với địa hình 1998 và $80 / 20$ địa hình 2018 , tăng trên sông Tiền lên $8 \%$ và giảm bên sông Hậu xuống $8 \%$. Dòng chảy mùa kiệt (min) và dòng chảy trung bình có xu thế tương tự, trong đó mùa kiệt giảm gần $50 \%$ từ $48 \mathrm{~m}^{3} / \mathrm{s}$ xuống $20 \mathrm{~m}^{3} / \mathrm{s}$ ), nhưng dòng chảy trung bình giảm $7 \%$ (từ $15 \%$ trên sông Hậu còn $9 \%$ ).

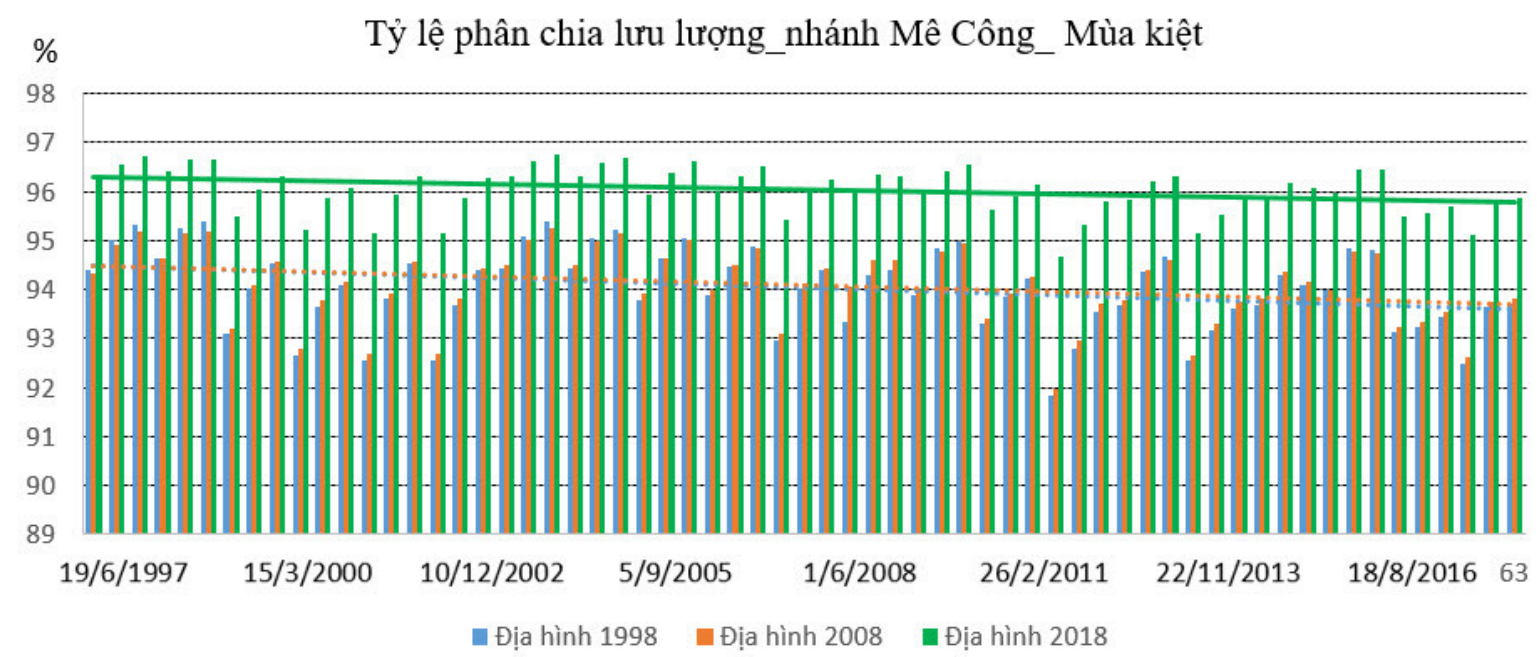

Hình 4. Kết quả tỷ lệ phân lưu nước qua nhánh Mê Công (sông Tiền) trong mùa lũ.

Hình 4 cho thấy tỷ lệ phân lưu trong mùa lũ qua sông Tiền ở địa hình năm 2018 cao hơn hẳn so với địa hình 1998 và 2008. Điều này cho thấy nếu tiếp tục khai thác cát như hiện nay ở trên sông Tiền sẽ còn có sự thay đổi lớn về tỷ lệ phân lưu trong tương lai. 


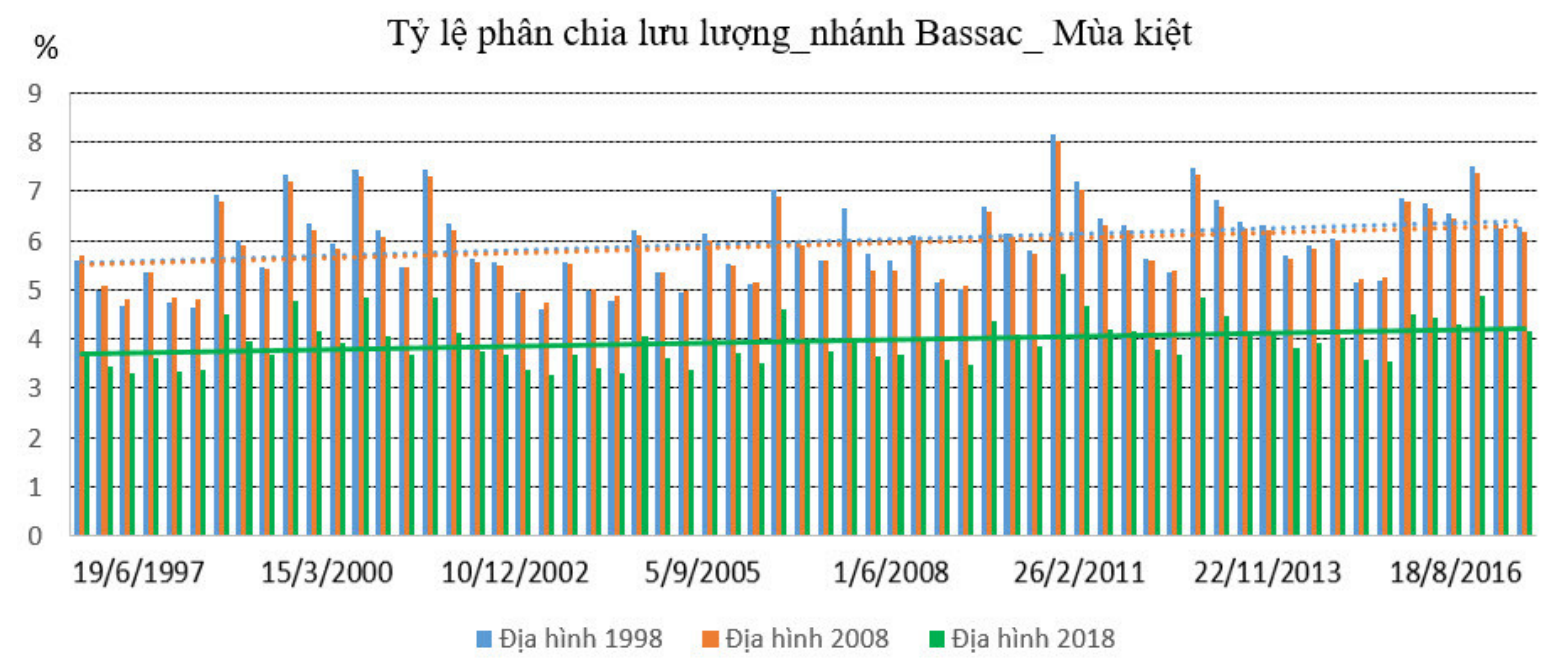

Hình 5. Kết quả tỷ lệ phân lưu nước qua nhánh Bassac (sông Hậu) trong mùa kiệt.

Tương tự, trong mùa kiệt ứng với địa hình 2018, Hình 5 cho thấy tỷ lệ chia nước cho sông Bassac (sông Hậu) giảm hẳn so với những năm trước đây, như vậy việc này sẽ ảnh hưởng trực tiếp đến dòng chảy của vùng sông Hậu và đặc biệt là khu vực vùng cao của phía Campuchia.

\subsection{Thay đổi quá trình trao đổi nước của sông Mê Công và biển Hồ}

Hình 6 cho thấy xu thế giảm sự trao đổi nước khá rõ rệt vào vùng biển Hồ khi có sự thay đổi về địa hình ở vùng hạ lưu sông Cửu Long. Mặt khác, lưu lượng nước chảy vào có phần khá ổn định, song lưu lượng chảy ra do phụ thuộc vào các nhánh sông khác đổ vào vùng biển Hồ nên có sự thay đổi theo hàng năm khá lớn. Ở giai đoạn lũ lớn 2000-2002, đây là 3 năm liên tiếp có lũ khá lớn về vùng ĐBSCL, nguồn nước chảy ra từ khu vực Tonle Sap khá rõ rệt, trong khi đó nguồn nước chảy vào vùng này không thay đổi nhiều, tương tự giai đoạn 20112013 và năm 2018 trở lại đây.

Bảng 3 cho thấy, hầu hết địa hình 2018 cho tỷ lệ dòng chảy vào và ra ít hơn so với 1998 và 2008. Nếu tính giá trị trung bình, dòng chảy vào trong giai đoạn 1998-2018 cho thấy, ứng với địa hình 1998, dòng chảy vào biển Hồ nhiều hơn 0,3 tỷ $\mathrm{m}^{3}$ so với địa hình năm 2018 , đồng thời dòng chảy ra cũng giảm 0,7 tỷ $\mathrm{m}^{3}$, và thời gian chảy vào giảm đi 4 ngày, thời gian chảy ra giảm đi 3 ngày.

Tuy nhiên, điều đáng quan tâm hơn ở đây là mức độ giao động của lượng nước chảy vào và chảy ra rất lớn, tùy thuộc theo điều kiện thủy văn của từng năm mà có sự khác biệt rất rõ rệt trong quá trình trao đổi nước của biển Hồ và Mê Công. Sự chênh lệch giữa dòng chảy vào như thể hiện ở bảng dưới đây cho thấy $\pm 2,7$ tỷ $\mathrm{m}^{3}$ tương ứng với địa hình 2018 và dòng chảy $\mathrm{ra} \pm 18$ tỷ $\mathrm{m}^{3}$ điều đó cho thấy, địa hình có tác động đến tỷ lệ trao đổi nước của biển Hồ và sông Mê Công một cách rõ rệt, tuy vậy thời gian chảy vào/ra không có sự khác biệt nhiều so với \pm 17 đến \pm 18 ngày. 

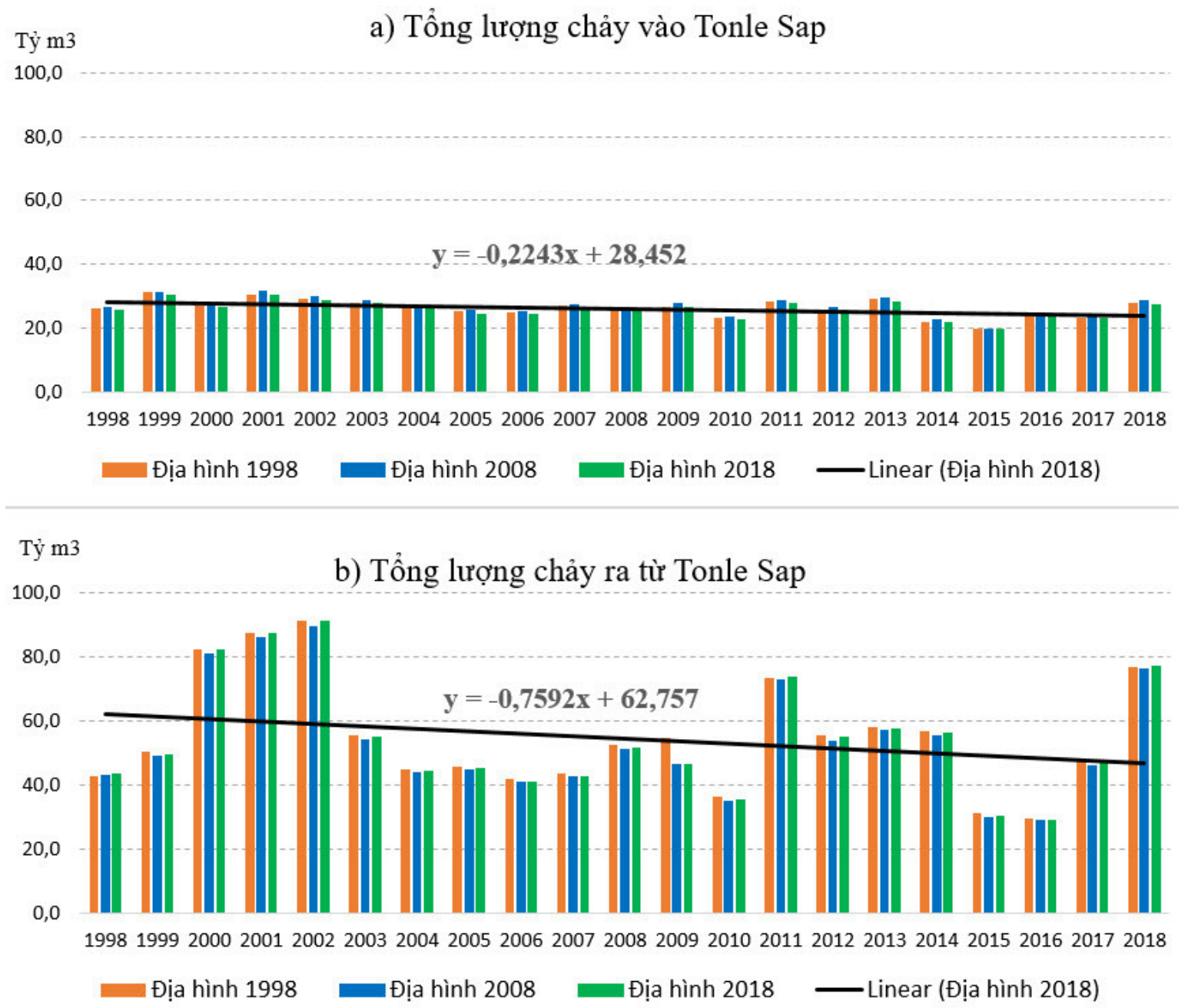

Hình 6. Kết quả tổng lượng nước chảy vào/ra biển Hồ theo các địa hình khác nhau.

Bảng 3. Tóm tắt kết quả tính dòng chảy và thời gian nước từ Mê Công ra/vào biển Hồ.

\begin{tabular}{|c|c|c|c|c|c|c|c|c|c|c|c|c|}
\hline \multirow[t]{2}{*}{ Năm } & \multicolumn{3}{|c|}{$\begin{array}{c}\text { Tổng lượng chảy vào } \\
\left.\text { (tỷ } \mathrm{m}^{3}\right)\end{array}$} & \multicolumn{3}{|c|}{$\begin{array}{c}\text { Tổng lượng chảy ra } \\
\left(\text { tỷ } \mathrm{m}^{3}\right)\end{array}$} & \multicolumn{3}{|c|}{$\begin{array}{c}\text { Thời gian chảy vào } \\
\text { (ngày) }\end{array}$} & \multicolumn{3}{|c|}{$\begin{array}{c}\text { Thời gian chảy ra } \\
\text { (ngày) }\end{array}$} \\
\hline & 1998 & 2008 & 2018 & 1998 & 2008 & 2018 & 1998 & 2008 & 2018 & 1998 & 2008 & 2018 \\
\hline 1998 & 26,1 & 26,5 & 25,8 & $-42,5$ & $-43,3$ & $-43,4$ & 127 & 128 & 127 & 238 & 237 & 238 \\
\hline 1999 & 31,1 & 31,5 & 30,5 & $-50,2$ & $-49,2$ & $-49,5$ & 145 & 145 & 146 & 220 & 220 & 219 \\
\hline 2000 & 26,9 & 27,9 & 26,7 & $-82,4$ & $-81,3$ & $-82,5$ & 105 & 108 & 108 & 230 & 227 & 227 \\
\hline 2001 & 30,5 & 31,6 & 30,3 & $-87,5$ & $-86,0$ & $-87,3$ & 105 & 109 & 109 & 260 & 256 & 256 \\
\hline 2002 & 29,1 & 30,0 & 28,6 & $-91,3$ & $-89,8$ & $-91,1$ & 99 & 99 & 100 & 266 & 266 & 265 \\
\hline 2003 & 27,9 & 28,6 & 27,8 & $-55,3$ & $-54,3$ & $-55,1$ & 121 & 121 & 122 & 244 & 244 & 243 \\
\hline 2004 & 26,5 & 27,1 & 26,1 & $-44,9$ & $-44,0$ & $-44,3$ & 125 & 129 & 130 & 241 & 237 & 236 \\
\hline 2005 & 25,2 & 25,8 & 24,7 & $-45,8$ & $-45,0$ & $-45,2$ & 115 & 112 & 116 & 250 & 253 & 249 \\
\hline 2006 & 24,8 & 25,5 & 24,6 & $-41,6$ & $-40,8$ & $-41,0$ & 131 & 134 & 135 & 234 & 231 & 230 \\
\hline 2007 & 26,9 & 27,6 & 26,5 & $-43,6$ & $-42,5$ & $-42,9$ & 149 & 153 & 154 & 216 & 212 & 211 \\
\hline 2008 & 26,1 & 26,8 & 25,9 & $-52,3$ & $-51,2$ & $-51,7$ & 126 & 126 & 126 & 240 & 240 & 240 \\
\hline 2009 & 26,5 & 27,9 & 26,5 & $-54,6$ & $-46,6$ & $-46,6$ & 127 & 143 & 142 & 238 & 222 & 223 \\
\hline 2010 & 23,1 & 23,5 & 23,0 & $-36,4$ & $-35,1$ & $-35,5$ & 134 & 144 & 143 & 231 & 221 & 222 \\
\hline
\end{tabular}




\begin{tabular}{|c|c|c|c|c|c|c|c|c|c|c|c|c|}
\hline \multirow[t]{2}{*}{ Năm } & \multicolumn{3}{|c|}{$\begin{array}{c}\text { Tổng lượng chảy vào } \\
\left.\text { (tỷ } \mathrm{m}^{3}\right)\end{array}$} & \multicolumn{3}{|c|}{$\begin{array}{c}\text { Tổng lượng chảy ra } \\
\left.\text { (tỷ } \mathrm{m}^{3}\right)\end{array}$} & \multicolumn{3}{|c|}{$\begin{array}{c}\text { Thời gian chảy vào } \\
\text { (ngày) }\end{array}$} & \multicolumn{3}{|c|}{$\begin{array}{c}\text { Thời gian chảy ra } \\
\text { (ngày) }\end{array}$} \\
\hline & 1998 & 2008 & 2018 & 1998 & 2008 & 2018 & 1998 & 2008 & 2018 & 1998 & 2008 & 2018 \\
\hline 2011 & 28,3 & 28,8 & 27,8 & $-73,5$ & $-72,9$ & $-73,8$ & 117 & 115 & 117 & 248 & 250 & 248 \\
\hline 2012 & 25,6 & 26,4 & 25,7 & $-55,4$ & $-53,7$ & $-54,9$ & 120 & 121 & 122 & 246 & 245 & 244 \\
\hline 2013 & 29,2 & 29,8 & 28,5 & $-58,2$ & $-57,0$ & $-57,5$ & 145 & 150 & 151 & 220 & 215 & 214 \\
\hline 2014 & 22,1 & 22,9 & 22,1 & $-56,8$ & $-55,6$ & $-56,5$ & 73 & 80 & 78 & 292 & 285 & 287 \\
\hline 2015 & 19,7 & 19,8 & 19,6 & $-31,0$ & $-30,0$ & $-30,4$ & 113 & 119 & 118 & 252 & 246 & 247 \\
\hline 2016 & 24,7 & 24,9 & 24,5 & $-29,5$ & $-29,1$ & $-29,2$ & 135 & 142 & 142 & 231 & 224 & 224 \\
\hline 2017 & 23,3 & 23,8 & 23,1 & $-47,4$ & $-46,3$ & $-47,0$ & 118 & 116 & 119 & 247 & 249 & 246 \\
\hline 2018 & 27,8 & 28,6 & 27,4 & $-76,9$ & $-76,2$ & $-77,2$ & 117 & 121 & 122 & 248 & 244 & 243 \\
\hline TB & 26,3 & 26,9 & 26,0 & $-55,1$ & $-53,8$ & $-54,4$ & 121 & 125 & 125 & 242 & 239 & 239 \\
\hline STD & 2,8 & 2,9 & 2,7 & 17,7 & 17,6 & 18,0 & 17 & 18 & 18 & 17 & 18 & 18 \\
\hline
\end{tabular}

Ghi chú: 1998, 2008, 2018 là tương ứng với địa hình của các năm; dấu (-) là dòng chảy ra khỏi biển Hồ; TB là giá trị trung bình, STD là giá trị lệch chuẩn.

\section{Kết luận}

+ Hạ thấp đáy sông trên hệ thống sông Cửu Long có sự tác động rất đáng kể đến tỉ lệ chia phân nước ở vùng Phnôm Pênh nơi có sự kết nối giữa Biển Hồ và sông Mê Công thông qua sông Tonle Sap, đồng thời là nơi phân lưu tại nút Chatomuk để chia nước về sông Tiền và sông Hậu. Dòng chảy vào biển Hồ có tổng lượng trung bình khoảng $26+2,9$ tỷ $\mathrm{m}^{3}$, tương ứng với thời gian chảy vào khoảng $125 \pm 18$ ngày, trong khi đó thời gian tổng lượng nước chảy ra khoảng $55,1 \pm 18$ tỷ $\mathrm{m}^{3}$ tương ứng với thời gian chảy ra $242 \pm 18$ ngày, điều này cũng khớp với các nghiên cứu trước đây.

+ Địa hình thay đổi ở trên hệ thống sông Cửu Long có tác động đến chế độ trao đổi nước ở vùng biển Hồ và tỷ lệ phân nước trên sông Tiền và sông Hậu, cụ thể lượng nước vào biển Hồ giảm trung bình trong giai đoạn $1998-2018$ là 0,3 tỷ $\mathrm{m}^{3}$ chảy vào và chảy ra là 0,7 tỷ $\mathrm{m}^{3}$. Tỷ lệ phân nước lưu lượng trong mùa lũ (max) chảy về sông Hậu (Bassac) giảm từ 9.819 $\mathrm{m}^{3} / \mathrm{s}$ tương ứng với địa hình 1998 xuống $6.545 \mathrm{~m}^{3} / \mathrm{s}$ ứng với địa hình 2018 . Như vậy, nước lũ chảy về sông Tiền tăng lên một cách đáng kể trong giai đoạn 2008-2018, trong khi đó giai đoạn 1998-2008 có xu hướng tăng hơn $\left(576 \mathrm{~m}^{3} / \mathrm{s}\right)$, tương ứng với tỷ lệ dòng chảy trên sông Tiền/sông Hậu là 72/28 với địa hình 1998 và $80 / 20$ địa hình 2018 . Dòng chảy mùa kiệt (min) và dòng chảy trung bình có xu thế tương tự, trong đó mùa kiệt giảm gần $50 \%$ từ $48 \mathrm{~m}^{3} / \mathrm{s}$ xuống $20 \mathrm{~m}^{3} / \mathrm{s}$ ), nhưng dòng chảy trung bình giảm $7 \%$ (từ $15 \%$ trên sông Hậu còn $9 \%$ ).

+ Sử dụng mô hình toán 1 chiều để phân tích tính toán cho hệ thống sông phức tạp là có tính khả thi, đồng thời kết quả cho thấy sự thay đổi đối với dòng chảy tại khu vực Phnôm Pênh một cách định lượng.

+ Khu vực bãi ngập lũ và địa hình lòng sông phía Campuchia đóng vai trò hết sức quan trọng đối với việc tính toán và dự báo vùng hạ du vùng đồng bằng sông Cửu Long, tuy nhiên toàn bộ tài liệu địa hình này chưa có sự cập nhật, do đó cần thiết trong tương lai phải vận dụng và nghiên cứu quốc tế và hợp tác quốc tế để bổ sung cho phần dữ liệu quan trọng nhưng còn thiếu này của vùng.

Đóng góp của tác giả: Xây dựng ý tưởng nghiên cứu: N.N.H; Lựa chọn phương pháp nghiên cứu: N.N.H; Xử lý số liệu: L.Q.Q.; Viết bản thảo bài báo: N.N.H.; Chỉnh sửa bài báo: L.Q.Q.

Lời cảm ơn: Nghiên cứu này được thực hiện dưới sự tài trợ của đề tài nghiên cứu khoa học cấp nhà nước thuộc chương trình KC08 mã số KC08.12/16-20 "Nghiên cứu tác động bất lợi 
của biến đổi hình thái lòng dẫn và hạ thấp mực nước hệ thống sông Cửu Long, đề xuất giải pháp giảm thiểu".

Lời cam đoan: Tập thể tác giả cam đoan bài báo này là công trình nghiên cứu của tập thể tác giả, chưa được công bố ở đâu, không được sao chép từ những nghiên cứu trước đây; không có sự tranh chấp lợi ích trong nhóm tác giả.

\section{Tài liệu tham khảo}

1. Penny, D. The Holocene history and development of the Tonle Sap, Cambodia. Quat. Sci. Rev. 2006, 25, 310-322. https://doi.org/10.1016/j.quascirev.2005.03.012.

2. Mekong River Commission. Overview of the Hydrology of the Mekong Basin, 2005, ISSN: 17283248.

3. Lamberts, D. Little impact, much damage: the consequences of mekong river flow alterations for the tonle sap ecosystem. Modern Myths of the Mekong, Helsinki University Of Technology, 2008, TKK \& Lamberts ISBN 978-951-22-9102-1.

4. MRCS/WUP-FIN. Tonle Sap Review and Integration Report. Final Draft. WUPFIN Phase 2 - Hydrological, Environmental and Socio-Economic Modelling Tools for the Lower Mekong Basin Impact Assessment. Mekong River Commission and Finnish Lower Mekong Modelling Project (WUP-FIN), Mekong River Commission 124 MRCS/WUP-FIN Environment Institute Consultancy Consortium, Vientiane, Lao PDR, 2005, pp. 113. Available online: http://www.eia.fi/wup-fin/wupfin2/publications.htm

5. Xu, Z.M.; Li, C.W.; Li, A.Q.; You, Z.Q.; Yao, W.; Chen, Y.S.; Huang, L.Y. Morphological Characteristics of Cambodia Mekong Delta and Tonle Sap Lake and Its Response to River-Lake Water Exchange Pattern. J. Water Res. Prot. 2020, 12, 275-302.

6. MRC. Annual Mekong Flood Report 2009, Mekong River Commission, Office of the Secretariat in Phnom Penh, 2010, pp. 80.

7. Hung, N.N.; Quan, L.Q.; Thanh, N.C. Tác động của hạ thấp đáy sông đến chế độ thủy triều trên hệ thống sông Cửu Long và đề xuất một số giải pháp quản lý. Tạp chi Khí turọng Thủy văn 2020, 715, 59-67. https://doi.org/10.36335/VNJHM.2020(715).59_ 67.

8. Dung, N.V.; Merz, B.; Bárdossy, A.; Thang, T.D.; Apel, H. Multi-objective automatic calibration of hydrodynamic models utilizing inundation maps and gauge data. Hydrol. Earth Syst. Sci. 2011, 15, 1339-1354. https://doi.org/10.5194/hess-151339-2011.

9. Manh, N.V.; Dung, N.V.; Hung, N.N.; Merz, B.; Apel, H. Large-scale suspended sediment transport and sediment deposition in the Mekong Delta. Hydrol. Earth Syst. Sci. 2014, 18, 3033-3053. https://doi.org/10.5194/hess-18-3033-2014.

10. Hùng, N.N.; Thành, N.C.; Quân, L.Q. Đánh giá tác động của hạ thấp lòng dẫn đến thoát lũ hệ thống sông cửu long giai đoạn 1998-2018. Tuyển tập báo cáo khoa học lần thứ 2, Chương trình KC08/16-20, 2018.

11. Toản, T.Q.; Tuấn, T.M. Biến động nguồn nước mùa lũ hàng năm do ảnh hưởng của các hồ đập thượng lưu và diễn biến lũ năm 2018 ở đồng bằng sông Cửu Long. Kỷ yếu hội thảo Khoa học công nghệ thủy lợi phục vụ phát triển bền vững vùng Nam Bộ, Nam Trung Bộ và Tây Nguyên, Viện Khoa học Thủy lợi Việt Nam, 2019.

12. Thắng, T.Đ.; Hoằng, T.B.; Toản, T.Q.; Vượng, N.Đ.; Tuấn, T.M.; Thịnh, L.V. Một số vấn đề về dòng chảy và xu thế mặn xâm nhập vùng đồng bằng sông Cửu Long. Kỷ yếu hội thảo Khoa học công nghệ thủy lợi phục vụ phát triển bền vững vùng Nam Bộ, Nam Trung Bộ và Tây Nguyên, Viện Khoa học Thủy lợi Việt Nam, 2019. 
13. Hùng, N.N. Nghiên cứu các giải pháp khoa học công nghệ để điều chỉnh và ổn định các đoạn sông có cù lao đang diễn ra biến động lớn về hình thái trên sông Tiền, sông Hậu. Viện khoa học Thủy lợi miền Nam, Kết quả đề tài KC08.21/11-15/2015.

14. https://www.phnompenhpost.com/national/sand-facility-allowed-operate.

\title{
The change of flow regime on branches: Tonle Sap River, Bassac River and the Mekong River, due to the bed degradation of the Cuu Long River system
}

\section{Nguyen Nghia Hung ${ }^{1 *}$, Le Quan Quan'}

1 Southern Institute of Water Resources Research, Vietnam; hungsiwrr@gmail.com; lequan2005@gmail.com

\begin{abstract}
In the previous articles, the bed degradation in the mainstream Mekong river has been analysed through the topographic comparison between three years bathymetry 1998 , 2008 and 2018 data. The content of this paper examines the impact of the Mekong bed lowering to the change of the distributary ratio at Chatomuk bifurcation where contributes water flow to three river branches, the Mekong (Tien river), Bassac (Hau river) and Great lake through Tonle Sap River. On the article, one-dimensional hydrodynamics model MIKE11 for entire Mekong delta river system had been applied, by using three bathymetries data $(1998,2008,2018)$ and simulating for the period time from 1998 to 2018 . The results showed the trend of water fluxes in and out reducing from the Mekong River to the sea and Tonle Sap lakes is quite clear with a standard deviation of about +2.9 billion $\mathrm{m}^{3} /$ year and the number of exchange days also changes by around +18 days in the period of 21 years (1998-2018). The proportion of water distribution in the Mekong River flowing to the Tien River tends to increase during the flood and dry season by around 7-9\%, whereas the Bassac River decreases, which makes the water regulation between regions change significantly.
\end{abstract}

Keywords: River bed degradation; Bifurcation flow ratio; Tonle Sap; Mekong Delta. 